\title{
Production and Evaluation of Porous Photocatalyst Concrete Filter (deNOx PCF) for NOx Reduction
}

\author{
Jung Joon Park, ${ }^{1}$ Gi Joon Park, ${ }^{1}$ Moon Kyung Kim, ${ }^{1}$ Wooseok Yeo, ${ }^{2}$ Jin Chul Joo, \\ and Jong Kyu Kim (D) ${ }^{4}$ \\ ${ }^{1}$ Department of Structural Engineering Research, Korea Institute of Civil Engineering and Building Technology, \\ Gyeonggi-do 10223, Republic of Korea \\ ${ }^{2}$ Department of Urban, Civil and Environmental Engineering, Shinhan University, Gyeonggi-do, Republic of Korea \\ ${ }^{3}$ Department of Civil and Environmental Engineering, Hanbat National University, Daejeon, Republic of Korea \\ ${ }^{4}$ Department of Urban and Real Estate Development Engineering, Shinhan University, Gyeonggi-do, Republic of Korea
}

Correspondence should be addressed to Jong Kyu Kim; jkim@shinhan.ac.kr

Received 27 September 2021; Revised 15 December 2021; Accepted 17 December 2021; Published 11 January 2022

Academic Editor: Bang Yeon Lee

Copyright ( 2022 Jung Joon Park et al. This is an open access article distributed under the Creative Commons Attribution License, which permits unrestricted use, distribution, and reproduction in any medium, provided the original work is properly cited.

\begin{abstract}
A porous photocatalyst concrete filter (deNOx PCF) is successfully manufactured to reduce $\mathrm{NOx}$ by mixing $\mathrm{TiO}_{2}$ photocatalyst with lightweight aerated concrete. From the results, $4 \%$ infusion rate of each foaming agent provided the smallest change of the height, and the optimal quality of the air bubbles can be produced by using foaming agent B with $4 \%$ of infusion rate. When $3 \%$ of $\mathrm{TiO}_{2}$ photocatalyst was mixed, less irregular and relatively homogeneous pores were formed on the surface with white color due to the proper amount of photocatalyst applied. For $3 \%$ of photocatalyst mixed with deNOx PCF, $1.03 \mu \mathrm{mol} / \mathrm{hr}$ of NO was reduced equivalent to $10.99 \%$ of $\mathrm{NO}$ reduction, suggesting that the $\mathrm{TiO}_{2}$ photocatalyst dispersed in the continuous and well-developed pores inside the specimen successfully performed the removal of NO flowing through deNOx PCF using synergistic effects of adsorption and photodegradation reaction. Finally, the specimen of porous deNOx PCF for reducing NOx developed in this study can be applied to various construction sites and the air quality can be solved by reducing NOx contributing to the formation of fine particles.
\end{abstract}

\section{Introduction}

Fine dust pollution is air pollution caused by fine particles (PM) which can be classified into PM2.5 (ultrafine dust) and PM10 (fine dust) based on the diameter of particles with a diameter of $2.5 \mu \mathrm{m}$ and $10 \mu \mathrm{m}$ or less, respectively [1]. Although the annual average concentration of PM2.5 in Seoul (South Korea) in 2018 decreased from $25 \mu \mathrm{g} / \mathrm{m}^{2}$ to $23 \mu \mathrm{g} / \mathrm{m}^{2}$ compared to 2017, potential human health risks due to environmental exposure to fine dust is still significant and stricter environmental regulation is required. Therefore, there is a need to develop reduction technologies and management plan for ultrafine dust. While primary fine dust, generated by direct emission because of human activity or natural processes, accounts for $30 \%$ of the total fine dust generated, secondary fine dust, generated by chemical reaction with primary fine dust under certain conditions in the air, contributes to $70 \%$ of the total fine dust generated [2]. The major secondary pollutants include NOx, SOx, VOCs, and CO; in particular, NOx contributes to the formation of fine particles and ground level ozone, both of which are associated with adverse health effects [3]. While NOx can be emitted naturally in the air without any human intervention, but it is mainly caused by artificial combustion activities such as exhaust gas from automobiles and factories [4]. NOx is also well known for causing respiratory diseases such as asthma and photochemical smog and acid rain [5].

Recent research has been actively conducted in decomposing secondary pollutants such as $\mathrm{NOx}$ and SOx to remove precursor materials of ultrafine dust and to apply photocatalyst directly into construction materials [6-8]. Since titanium dioxide $\left(\mathrm{TiO}_{2}\right)$, one of the photocatalyst, is a 
functional substance that catalyzes the reduction of NOx in the atmosphere through photolysis [9], NOx in the air can be substantially reduced due to the photocatalysis reactions when $\mathrm{TiO}_{2}$ is coated on the surface of the concrete [10]. The removal efficiency of NOx by photocatalysis can be maximized when the $\mathrm{TiO}_{2}$-coated cement is used in the road and the buildings through the greater surface area exposure to direct sunlight [11]. Since the lightweight aerated concrete with continuous pores inside the specimen by simultaneously mixing water, cement, and air bubbles of fine particle size is different from ordinary concrete [12], lightweight aerated concrete has been used as insulation or soundproofing materials and is not widely used as a filter to remove air pollutants [13].

In this study, a porous photocatalyst concrete filter (deNOx PCF) is manufactured to reduce NOx by mixing $\mathrm{TiO}_{2}$ photocatalyst with present lightweight aerated concrete. As both porosity and volume of continuous pores inside the porous concrete are determined by the types and the amount of foaming agent, the optimal conditions should be determined to manufacture high-quality porous concrete filters. Then, porous photocatalyst concrete filter are prepared according to the derived optimal condition of both type and amount of forming agents and mixing amount of $\mathrm{TiO}_{2}$ photocatalyst. The surface characteristics of continuous pores formed in the manufactured deNOx PCF were analyzed, and the NO removal efficiencies of various deNOx PCF were evaluated by conducting a nitric oxide removal experiment based on ISO-22197-1 [14].

\section{Materials and Methods}

2.1. Materials. Normal Portland cement (Class 1, SsangYong Cement, Korea) was used as a main material for the porous concrete filter specimen, P-25 (Degussa) was used as a $\mathrm{TiO}_{2}$ photocatalyst, and three different types of foaming agent (A, B, C, Korea) were used to form pores inside the concrete filter. The types and properties of foaming agents are summarized in Table 1. P-25 is nanosized $\mathrm{TiO}_{2}(100 \mathrm{~nm}$ on average) photocatalyst with an anatase crystal and a rutile crystal structure with a ratio of $7: 3$ and a specific surface area of approximately $55-70 \mathrm{~m}^{2} / \mathrm{g}$. Porous photocatalyst concrete filter specimens (deNOx PCF) were manufactured in rectangle with the size of $10 \mathrm{~cm}(W) \times 5 \mathrm{~cm}(L) \times 1 \mathrm{~cm}(H)$ required by $\mathrm{NO}$ removal performance evaluation apparatus manufactured based on NO ISO-22197-1 [14].

\subsection{Evaluation of Optimal Bubble Generation Conditions.} To adsorb and photodegrade NOx stably using deNOx PCF, development of numerous pores inside and outside of deNOx PCF is significant and the pores in deNOx PCF can be generated when water, air, and foaming agents are properly mixed. The bubble generator consists of an air controller, a flow rate controller, an inlet of foaming agent, a revolving type bubble generator, and an outlet of bubbles (NBG-Nano Bubble Generator, SBE\&E, Korea). The detail procedures are as follows. The generator can produce up to $0.1 \mathrm{~m}^{3} / \mathrm{min}$ of air bubbles with the size of less than $500 \mathrm{~nm}$. A
TABLE 1: Types and properties of foaming agents.

\begin{tabular}{lccc}
\hline & Foaming agent & Foaming agent & Foaming agent \\
& $\mathrm{A}$ & $\mathrm{B}$ & $\mathrm{C}$ \\
\hline Type & Synthesis & Synthesis & Vegetable \\
$\mathrm{pH}$ & $6 \sim 8$ & $6 \sim 8$ & $6 \sim 8$ \\
Colors & Light tint & Light tint & Bitumen \\
$\begin{array}{l}\text { Specific } \\
\text { gravity }\end{array}$ & $1 \pm 0.5$ & $1 \pm 0.5$ & $1 \pm 0.5$ \\
$\begin{array}{l}\text { Density }(\mathrm{g} / \\
\left.\mathrm{cm}^{3}\right)\end{array}$ & 1.14 & 1.02 & 2.7 \\
\hline
\end{tabular}

consistent amount of air, water, and foaming agents was flowed into the generator through air, flow, and air bubble controllers installed inside the generator. Air, water, and foaming agents were mixed at $1: 1: 1$ ratio (by volume) to produce uniform size of nanobubbles less than $500 \mathrm{~nm}$. As both type and amount of foaming agent affected the density and the retention time of the air bubble generated, the experiment was performed with varying conditions of types and the infusion rate of the foaming agent injected into the bubble generator.

2.3. Producing Method of Porous Photocatalyst Concrete Filter (deNOx PCF). The optimal nanosized bubbles produced using the bubble generator were mixed into the porous concrete specimen, taking up $7 \%$ of the total weight of the specimen, to manufacture deNOx PCF specimen before mixing with $\mathrm{TiO}_{2}$ photocatalyst (P-25). As summarized in Table $2, \mathrm{TiO}_{2}$ photocatalyst were mixed with $0 \%, 3 \%$, and $5 \%$ of the total weight of the porous concrete specimen. To manufacture the deNOx PCF specimens, photocatalyst was mixed into a cement paste composed of W/C (water/cement weight ratio) $=0.3$, and then, the dry mixing was performed for 5 minutes. The pregenerated air bubbles were inserted into cement paste and mixed. Finally, the specimen preparation was completed by pouring cement paste containing photocatalyst and bubbles into molds for NOx removal.

\subsection{Analysis of Internal and External Surface Characterization} of deNOx PCF. Well-developed pores inside and outside of the structure are significant since deNOx PCF not only works as a photocatalyst but also works as a filter, NOx in the air is removed through pores formed inside and outside. $\mathrm{TiO}_{2}$ particles on the outer surface of the structure directly reduce NOx in the air, but pores inside and outside the structure adsorb NOx in the air. Figure 1 shows the plausible mechanism of reducing hazardous substances (NOx and NH3) in air through the deNOx PCF. To analyze the degree of generation of pores inside and outside the specimen based on the different mixing conditions, scanning electron microscope (SEM) images were applied at 5,000 and 10,000 magnifications. Under the vacuum condition, microscopic electromagnetic waves of $100 \mathrm{~nm}$ were injected to the surface of the deNOx PCF specimen to observe the form and microstructure of the specimen by analyzing the signals of various wavelengths such as secondary electrons, reflective electrons, transmission electrons, visible light, infrared rays, 
Table 2: Producing conditions of deNOx PCF by a different mixing amount of $\mathrm{TiO}_{2}$.

\begin{tabular}{lccc}
\hline Type & Water-cement ratio $(\mathrm{W} / \mathrm{C})$ & Bubble mixing amount $(\mathrm{C} * \%)$ & $\mathrm{TiO}_{2}$ mixing amount $(\mathrm{C} * \%)$ \\
\hline 1 & 0.3 & 7 & 0 \\
2 & 0.3 & 7 & 3 \\
3 & 0.3 & 7 & 5 \\
\hline
\end{tabular}

and $\mathrm{X}$ rays coming out of the surface. In order to analyze the degree of continuous pore formation of deNOx PCF according to the photocatalyst mixing rate, both compressive strength test (KS F 2405) and permeability test (KS F 239) of deNOx PCF specimen were performed.

\subsection{Measurement of NO Reduction Rate by a Different Mixing} Amount of $\mathrm{TiO}_{2}$ Photocatalyst. An experiment was conducted to compare and analyze the NO reduction performance of deNOx PCF containing $0 \%, 3 \%$, and $5 \%$ of $\mathrm{TiO}_{2}$ photocatalyst of the total porous concrete specimen, in accordance with the Nitrogen Oxide Removal Performance Evaluation (ISO-22197-1). The reaction apparatus consisting of gas inlet, reactor, UV lamp, and reactive gas analysis part is displayed in Figure 2. A deNOx PCF with the size of $10 \mathrm{~cm}(W) \times 5 \mathrm{~cm}(L) \times 1 \mathrm{~cm}$ $(H)$ was injected into the NO reduction experimental device manufactured in accordance with ISO standard, as represented in Figure 2. To compare and analyze the NO reduction rate of deNOx PCF specimens, four specimens containing different ratios of photocatalyst (i.e., $0 \%, 3 \%$, and $5 \%$ and regular concrete specimen) were analyzed and compared. The temperature inside the generator was maintained at $25^{\circ} \mathrm{C}$, and nitrogen gas was injected through gas inlet to keep the nitrogen concentration to $1 \mathrm{mg} / \mathrm{L}$ for 90 minutes. For the first 30 minutes of reaction, experiments were conducted under a darkroom without UV irradiation to induce the adsorption of specimens; then, UV lamps $\left(10 \mathrm{~W} / \mathrm{m}^{2}\right)$ were irradiated for one hour to evaluate the NO reduction efficiency of photocatalyzed porous specimen (i.e., deNOx PCF). The experimental conditions are summarized in Table 3 . The concentrations of $\mathrm{NO}_{\mathrm{x}}$ and $\mathrm{NO}_{2}$ were measured every 1 minute in real time, and the $\mathrm{NO}$ reduction rate and the amount were analyzed by converting $\mathrm{NO}_{2}$ volume rate and $\mathrm{NO}$ concentration. Three specimens were analyzed for each condition, and the mean values of NO removal efficiencies were obtained.

\section{Results and Discussion}

3.1. Determination. To form the pores inside and outside the deNOx PCF effectively, an experiment was conducted to determine the optimal bubble generation condition according to both type and infusion rate of foaming agents. The generated bubbles under the different conditions were monitored over 6 hours, and the results are displayed in Figure 3. For foaming agent $\mathrm{A}$, the height of the foaming agent was significantly reduced over time, as displayed Figure 3(a). The height of foaming agent $\mathrm{C}$ was not reduced notably, as illustrated in Figure 3(c), but the volume of the

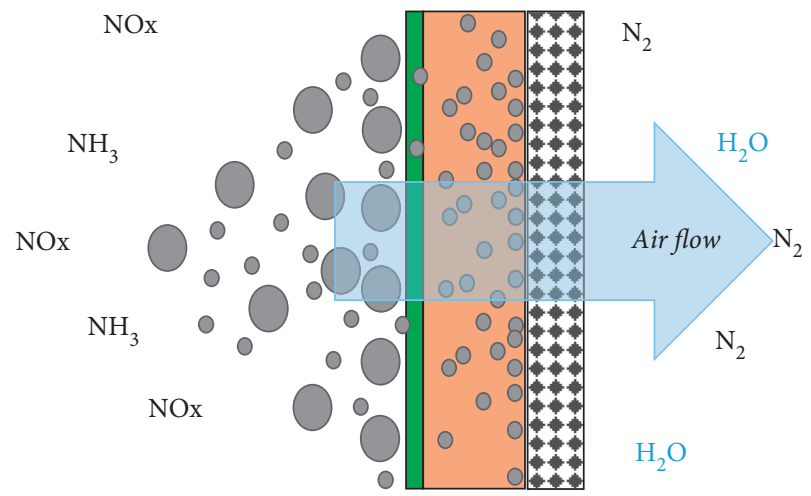

FIGURE 1: Plausible mechanism of reducing hazardous substances $\left(\mathrm{NOx}, \mathrm{NH}_{3}\right)$ in air through the deNOx PCF.

bubbles was significantly reduced, suggesting that foaming agent $\mathrm{C}$ was considered to be of poor quality.

Based on the results of the experiment, the optimal infusion rate is $4 \%$ as the formation of the bubbles were stable under such condition. When $5 \%$ of foaming agent was injected, water, air, and the foaming agent were not mixed properly compared to $4 \%$ of the foaming agent was injected. When the infusion amount was lower than 3\%, the amount of water was greater than the foaming agent, leading to the poor quality of bubbles. As summarized in Figure 3(d) for $4 \%$ infusion rate of each foaming agent, the height of foaming agent $B$ was reduced from $14.7 \mathrm{~cm}$ to $9.1 \mathrm{~cm}$, which provided the smallest change of the height, except for the predetermined poor foaming agent C. Consequently, it is considered that the optimal quality of the air bubbles can be produced by using foaming agent $\mathrm{B}$ with $4 \%$ of the infusion rate.

3.2. Surface Characterization of deNOx PCF. The pictorial view of surface for deNOx PCF specimen was revealed in Figure 4 . When the $0 \%$ of photocatalyst was mixed with the porous concrete filter, the irregular and heterogeneous pores were formed on the surface with the concrete textures. When $3 \%$ of photocatalyst was mixed, less irregular and relatively homogeneous pores were formed on the surface with white color due to the proper amount of photocatalyst applied. When $5 \%$ of photocatalyst was mixed, the photocatalyst interrupted the formation of pores and the surface was white due to the excessive amounts of photocatalyst.

As is evident in Figure 5, SEM images indicated that the irregular and heterogeneous pores less than $500 \mathrm{~nm}$ were observed at 5,000-10,000 magnifications of porous deNOx PCF specimen manufactured with $0 \%$ of photocatalyst injected. However, less irregular and relatively 


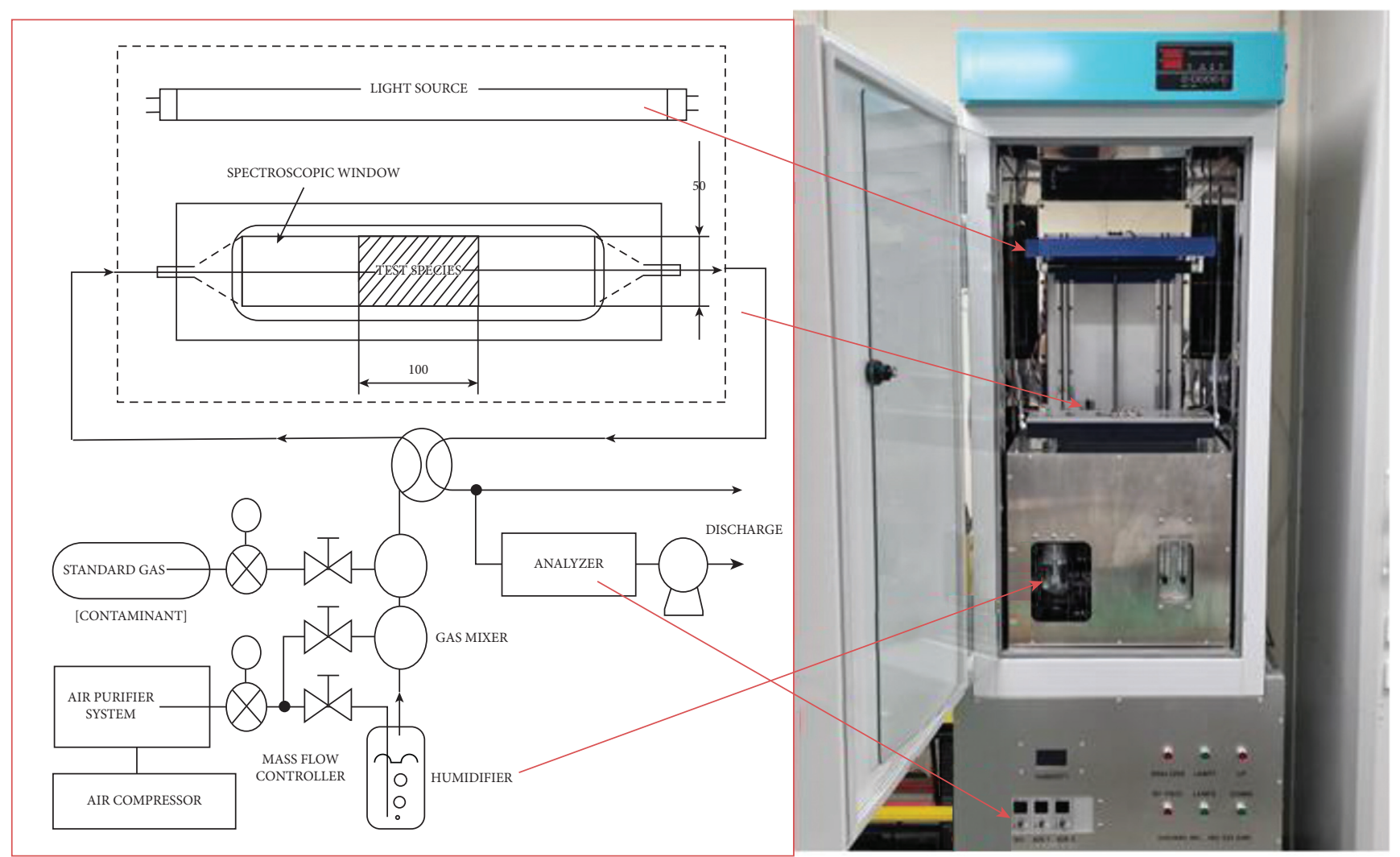

FIGURE 2: Nitrogen oxide reduction performance evaluation apparatus using deNOx PCF.

TABLE 3: Nitrogen oxide reduction performance evaluation test conditions (ISO-22197-1).

\begin{tabular}{lccc}
\hline NO conc. $(\mathrm{ppmv})$ & $\mathrm{UV}$ intensity $\left(\mathrm{W} / \mathrm{m}^{2}\right)$ & Temperature $\left({ }^{\circ} \mathrm{C}\right)$ & Reaction time $(\mathrm{min})$ \\
\hline 1 & 10 & $25 \pm 2$ & 90
\end{tabular}

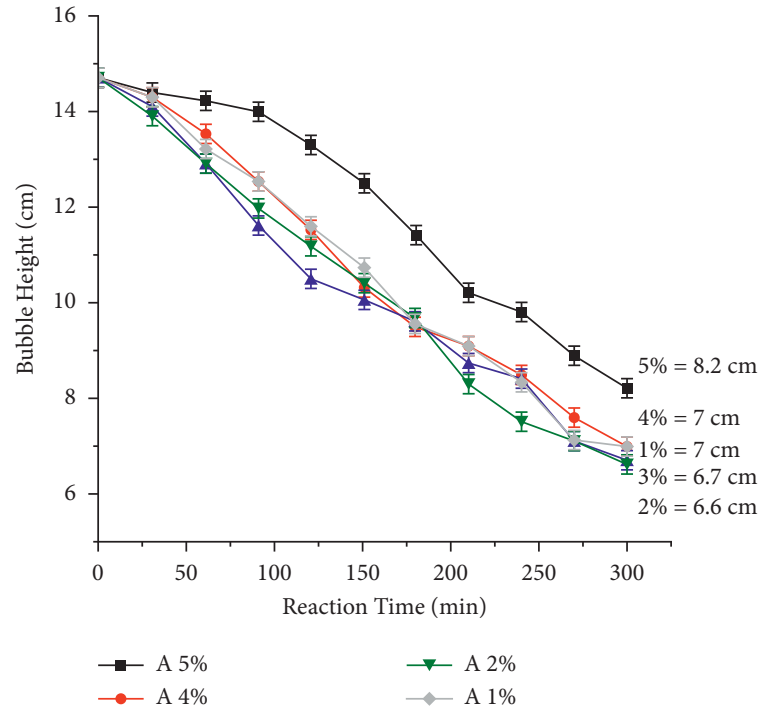

(a)

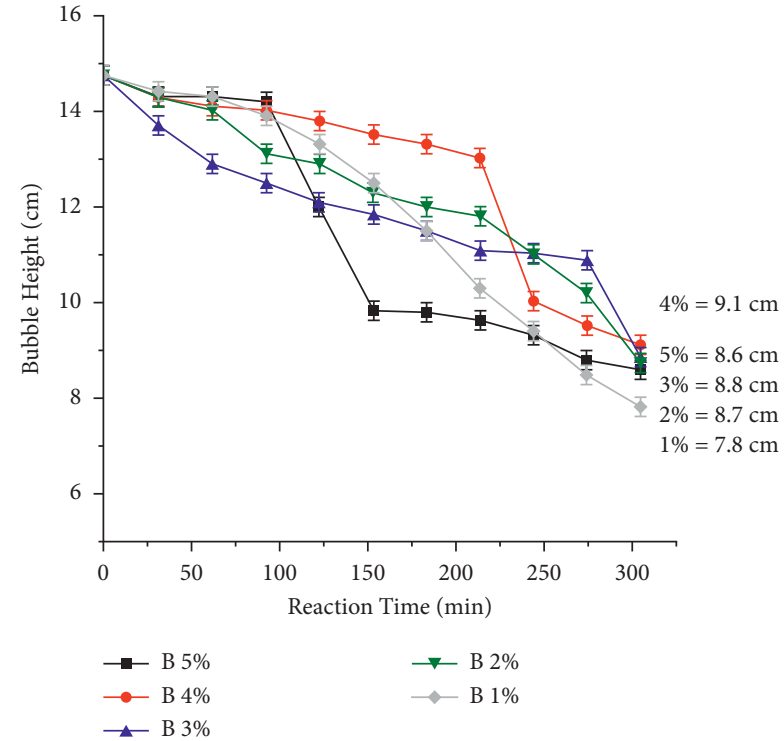

(b)

FIgURe 3: Continued. 


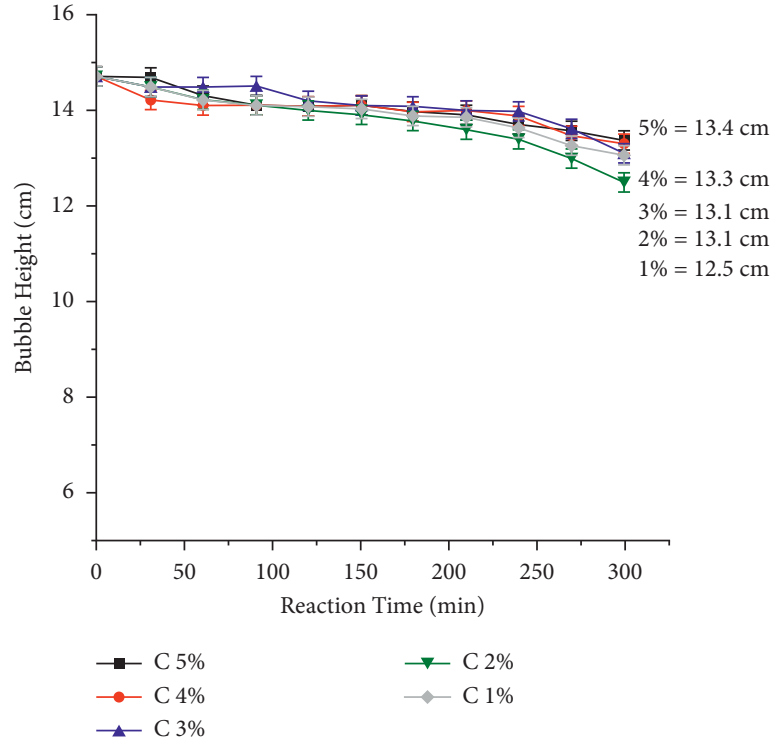

(c)

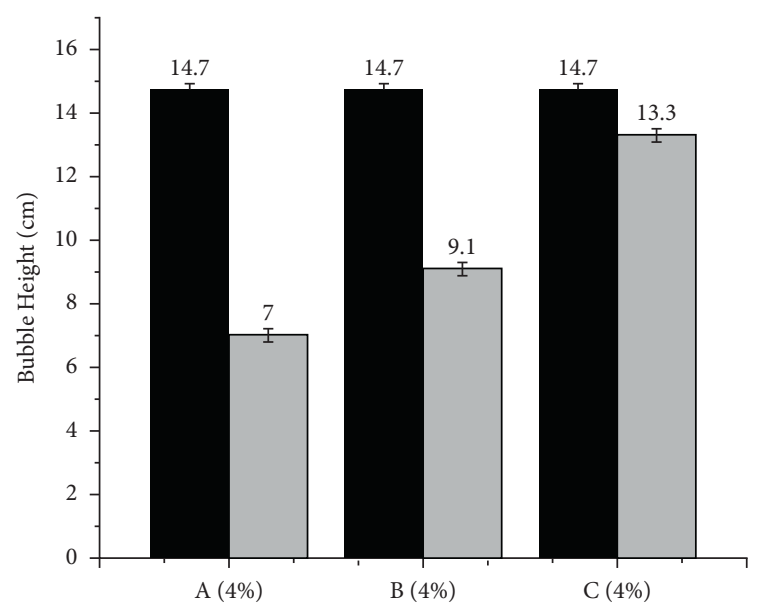

(d)

Figure 3: Changes in bubble height for different foaming agents with time by different generation conditions. (a) Foaming Agent A. (b) Foaming Agent B. (c) Foaming Agent C. (d) Foaming Agent A, B, and C 4\%.

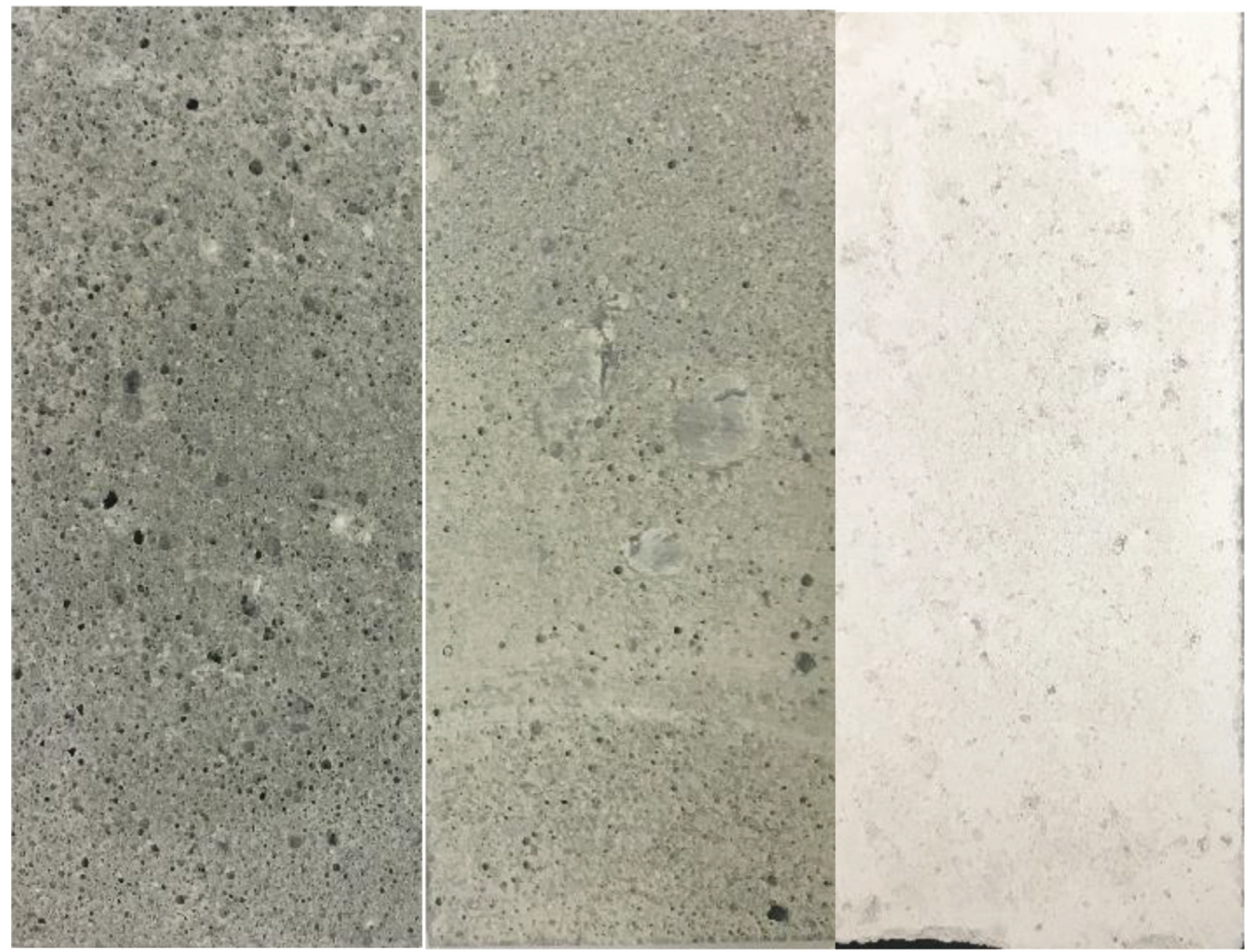

Figure 4: Pictorial view of surface for deNOx PCF specimens (left $\mathrm{TiO}_{2} 0 \%$, middle $\mathrm{TiO}_{2} 3 \%$, and right $\mathrm{TiO}_{2} 5 \%$ ). 


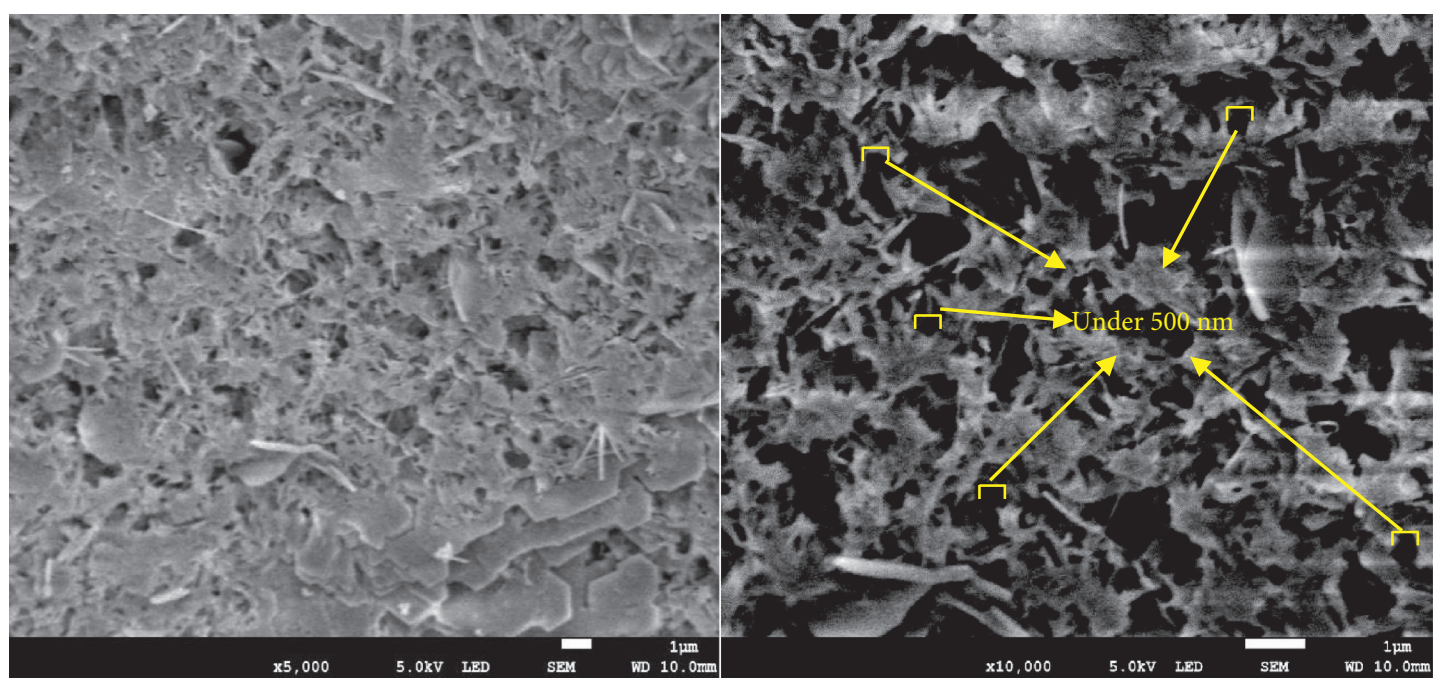

(a)

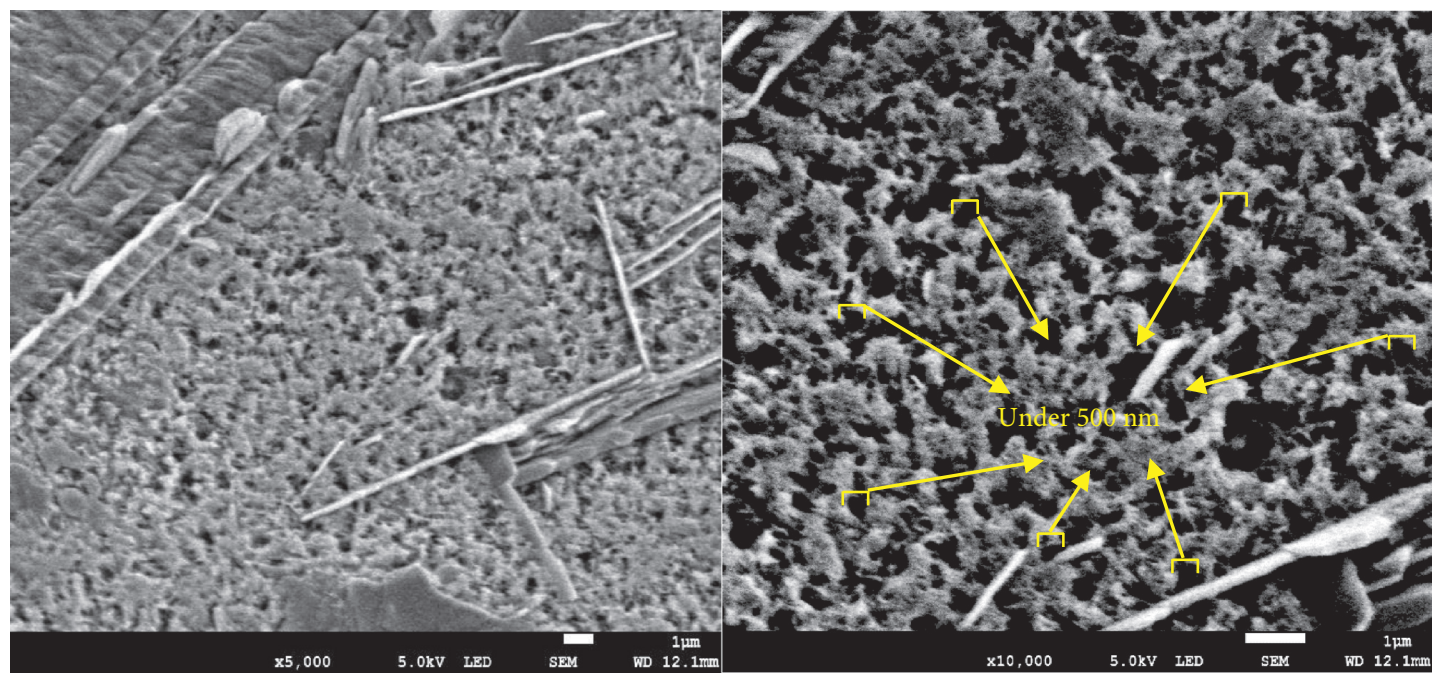

(b)
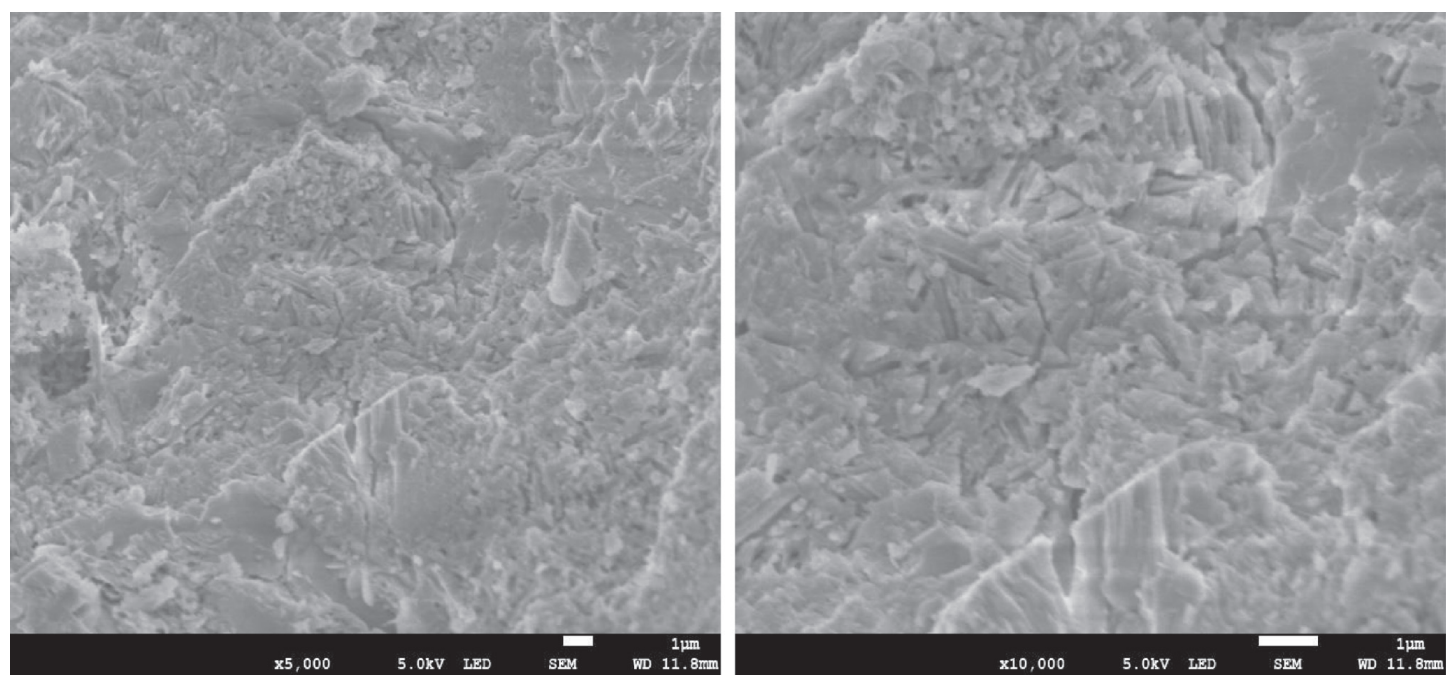

(c)

Figure 5: SEM images with different amounts of photocatalyst applied (left 5,000x and right 10,000x). (a) Porous concrete filter (TiO ${ }_{2} 0 \%$ ). (b) deNOx PCF $\left(\mathrm{TiO}_{2} 3 \%\right)$. (c) deNOx PCF $\left(\mathrm{TiO}_{2} 5 \%\right)$. 


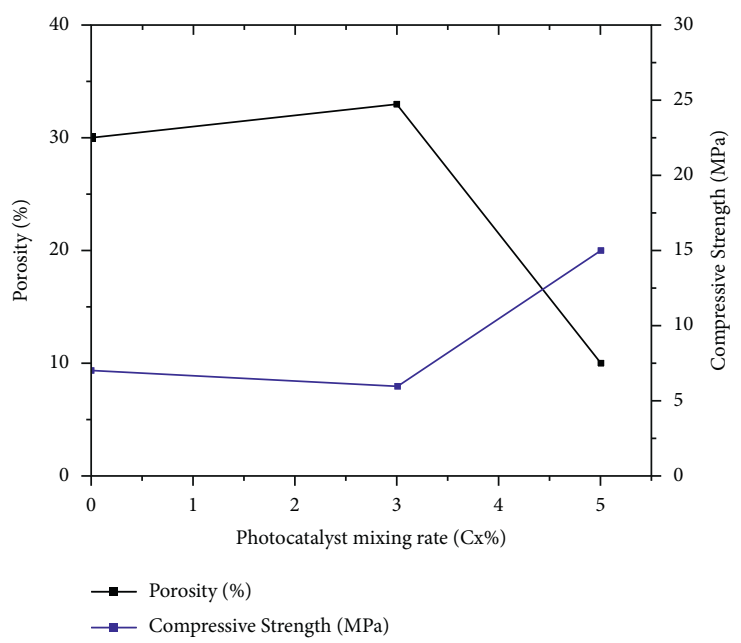

Figure 6: Permeability and compressive strength test results of deNOx PCF.

homogeneous pores less than $500 \mathrm{~nm}$ were observed at 5,000-10,000 magnifications of porous deNOx PCF specimen manufactured with $3 \%$ of photocatalyst injected. When $5 \%$ of photocatalyst is mixed, the pores were not formed due to the interruption and clogging caused by excessive photocatalyst, leaving the internal part of the specimen to be filled. These results suggest that optimal deNOx PCF with regular and homogeneous pores less than $500 \mathrm{~nm}$ can be manufactured when $3 \%$ of catalyst is mixed to the total weight of the specimen. Figure 6 displays the results of permeability and compressive strength test of deNOx PCF. In the case of PCF injected with $0 \%$ and $3 \%$ photocatalyst, the permeability was measured to be high while the compressive strength was measured to be low. These results are mainly attributed to the fact that pores of $500 \mathrm{~nm}$ or less are continuously formed inside the PCF, so the permeability is high while the compressive strength is low. On the contrary, in the case of PCF injected with $5 \%$ photocatalyst, few pores were formed inside the deNOx PCF. Therefore, general concrete with high compressive strength but low water permeability was manufactured.

3.3. Comparison of NOx Reduction Efficiency. Figure 7 and Table 4 show the results of comparing the NOx removal efficiency according to the $\mathrm{TiO}_{2}$ photocatalyst injection amount in the deNOx PCF specimen. For the regular concrete without forming agent (control), the reduction amount of NOx per hour was $0.09 \mu \mathrm{mol} / \mathrm{hr}$ equivalent to the $1.06 \%$ of total amount of NO. When $0 \%$ of $\mathrm{TiO}_{2}$ photocatalyst was mixed into the specimen, $0.32 \mu \mathrm{mol} / \mathrm{hr}$ was reduced equivalent to the $3.88 \%$ of NO reduction. These results can be mainly due to the fact that the continuous pores inside the specimen adsorbed significant amount of NO compared to the regular concrete. When $3 \%$ of photocatalyst was mixed to the specimen, $1.03 \mu \mathrm{mol} / \mathrm{hr}$ of NO was reduced equivalent to $10.99 \%$ of NO reduction. The $\mathrm{TiO}_{2}$ photocatalyst dispersed in the continuous and well- developed pores inside the specimen successfully performed the removal of NO flowing through deNOx PCF using synergistic effects of adsorption and photodegradation reaction. When $5 \%$ of $\mathrm{TiO}_{2}$ photocatalyst was mixed into deNOx PCF specimen, $0.58 \mu \mathrm{mol} / \mathrm{hr}$ of $\mathrm{NO}$ was reduced equivalent to $6.28 \%$ of $\mathrm{NO}$ reduction. Compared to the $3 \%$ of photocatalyst, $\mathrm{NO}$ reduction efficiency of $5 \%$ of $\mathrm{TiO}_{2}$ photocatalyst is lower mainly due to the failure in forming continuous pores resulting in the limited adsorption and photodegradation reaction. From the aforementioned results, the optimal deNOx PCF can be produced when photocatalyst can be injected 3\% out of the total weight of the specimen.

3.4. Comparison of Reaction Rate Constant. The NO reduction results of deNOx PCF specimen manufactured with different amounts of photocatalyst injection were described using the primary reaction of Langmuir-Hinshelwood (L-H) to analyze the reaction rate constant $\left(K_{\mathrm{app}}\right)$. The NO reduction reaction using deNOx PCF specimen is comparable by pseudoprimary $\mathrm{L}-\mathrm{H}$ rate equation [15]:

$$
\ln \frac{C}{C_{0}}=-K_{\text {app }} t,
$$

where $C_{0}$ is the initial concentration of $\mathrm{NO}$ in the atmosphere (ppmv), $C$ is the concentration of NO after the experiment (ppmv), and $K_{a p p}$ is the constant of reaction rate $\left(\min ^{-1}\right)$.

As summarized in Table 5, the reaction rate of deNOx PCF specimens with $3 \%$ and $5 \%$ of photocatalyst resulted in reaction rate constant of $0.0555 \mathrm{~min}^{-1}$ and $0.032 \mathrm{~min}^{-1}$, respectively. The higher reaction rate of the specimen containing $3 \%$ of $\mathrm{TiO}_{2}$ is mainly attributed to the relatively homogeneous dispersion of photocatalyst in the continuous pores inside the specimen, causing active adsorption and photodegradation reactions. The regular concrete specimen with $0 \%$ photocatalyst injection was 


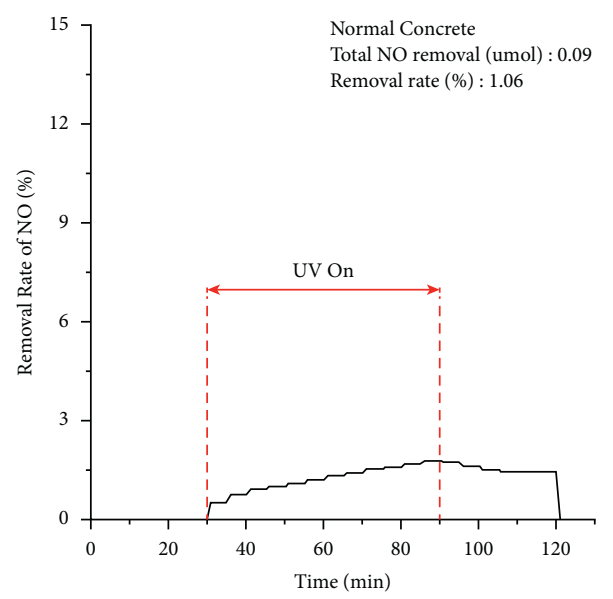

(a)

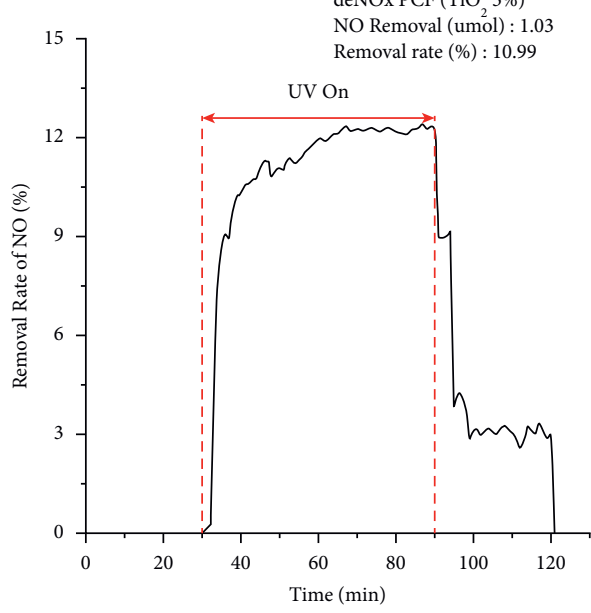

(c)

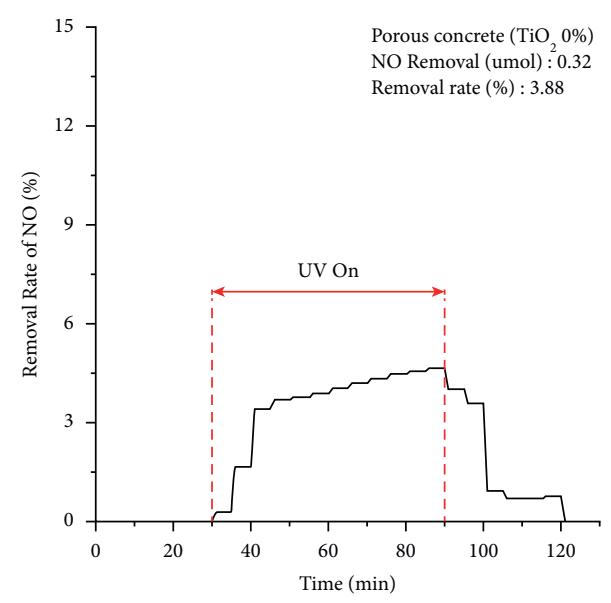

(b)

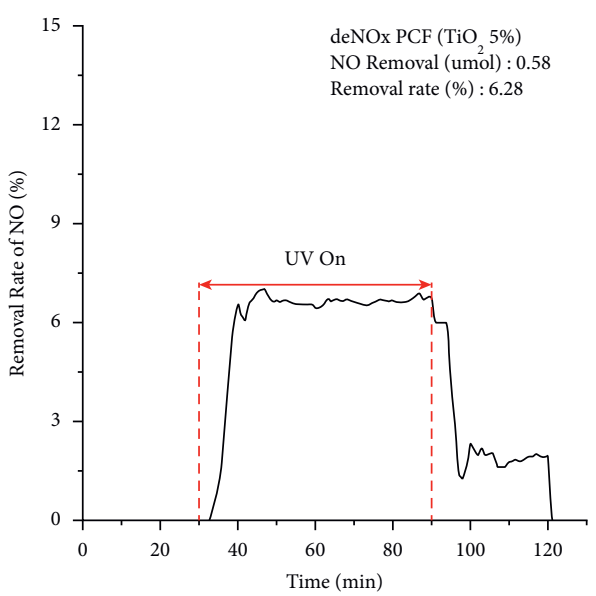

(d)

Figure 7: Comparison of NO reduction with a different $\mathrm{TiO}_{2}$ mixing amount into deNOx PCF specimen. (a) Normal concrete. (b) Porous concrete $\left(\mathrm{TiO}_{2}\right.$ 0\%). (c) deNOx PCF $\left(\mathrm{TiO}_{2} 3 \%\right)$. (d) deNOx PCF $\left(\mathrm{TiO}_{2} 5 \%\right)$.

TABLE 4: Results of comparative evaluation of NO reduction by each different specimen.

\begin{tabular}{lccc}
\hline & Total supplied NO amount $(\mu \mathrm{mol})$ & $\begin{array}{c}\text { NO reduction amount } \\
(\mu \mathrm{mol} / \mathrm{h})\end{array}$ & $\begin{array}{c}\text { Total NO removal rate } \\
(\%)\end{array}$ \\
\hline Portland cement concrete filter (no porous, no $\left.\mathrm{TiO}_{2}\right)$ & 8.22 & 0.09 & 1.06 \\
Lightweight aerated concrete filter (porous, no $\left.\mathrm{TiO}_{2}\right)$ & 8.26 & 0.32 & 3.88 \\
deNOx PCF (porous, 3\% of $\left.\mathrm{TiO}_{2}\right)$ & 9.36 & 1.03 & 10.99 \\
deNOx PCF (porous, 5\% of $\left.\mathrm{TiO}_{2}\right)$ & 9.24 & 0.58 & 6.28 \\
\hline
\end{tabular}

TABLE 5: Kinetic results and NO reduction reaction constant.

\begin{tabular}{lc}
\hline $\mathrm{TiO}_{2}$ mixing amount (\%) & $\mathrm{k}_{\mathrm{app}}\left(\mathrm{min}^{-1}\right)$ \\
\hline 3 & 0.0555 \\
5 & 0.032 \\
\hline
\end{tabular}

excluded as it did not show sufficient reduction of NO concentration.

\section{Conclusions}

In this study, a porous photocatalyst concrete filter (deNOx $\mathrm{PCF}$ ) is manufactured to reduce $\mathrm{NOx}$ by mixing $\mathrm{TiO}_{2}$ photocatalyst with lightweight aerated concrete. Then, the surface characteristics of continuous pores formed in the manufactured deNOx PCF were analyzed, and the NO removal efficiencies of various deNOx PCF were evaluated by conducting a nitric oxide removal experiment based on ISO22197-1. From the results, $4 \%$ infusion rate of each foaming agent provided the smallest change of the height, and the optimal quality of the air bubbles can be produced by using foaming agent $\mathrm{B}$ with $4 \%$ of the infusion rate. When $3 \%$ of photocatalyst was mixed, less irregular and relatively homogeneous pores were formed on the surface with white color due to the proper amount of photocatalyst applied. However, when $5 \%$ of photocatalyst was mixed, the 
photocatalyst interrupted the formation of pores and the surface was white due to the excessive amounts of photocatalyst. These results suggest that optimal deNOx PCF with regular and homogeneous pores less than $500 \mathrm{~nm}$ can be manufactured when $3 \%$ of catalyst is mixed to the total weight of the specimen. For $3 \%$ of photocatalyst mixed with deNOx PCF, $1.03 \mu \mathrm{mol} / \mathrm{hr}$ of $\mathrm{NO}$ was reduced equivalent to $10.99 \%$ of NO reduction, suggesting that the $\mathrm{TiO}_{2}$ photocatalyst dispersed in the continuous and well-developed pores inside the specimen successfully performed the removal of NO flowing through deNOx PCF using synergistic effects of adsorption and photodegradation reaction. Also, the higher reaction rate of the specimen containing 3\% of $\mathrm{TiO}_{2}$ is mainly attributed to the relatively homogeneous dispersion of photocatalyst in the continuous pores inside the specimen, causing active adsorption and photodegradation reactions. The aforementioned results, the optimal deNOx PCF can be produced when photocatalyst can be injected $3 \%$ out of the total weight of the specimen. Finally, the specimen of porous deNOx PCF for reducing NOx developed in this study can be applied to various construction sites and the air quality can be solved by reducing NOx contributing to the formation of fine particles [16].

\section{Data Availability}

The data used to support the findings of this study are included within the article.

\section{Conflicts of Interest}

The authors declare that there are no conflicts of interest regarding the publication of this paper.

\section{Acknowledgments}

This work was supported by the Korea Agency for Infrastructure Technology Advancement (KAIA) grant funded by the Ministry of Land, Infrastructure and Transport (Grant 21CTAP-C157328-02).

\section{References}

[1] J. H. Seinfeld and S. H. Pandis, Atmospheric Chemistry and Physics: From Air Pollution to Climate Change, John Wiley \& Sons, New Jersey, Hoboken, 3rd edition, 2016.

[2] M. Horgnies, I. Dubois-Brugger, N. J. Krou, I. BatonneauGener, T. Belin, and S. Mignard, "Reactivity of NO2 and CO2 with hardened cement paste containing activated carbon," The European Physical Journal-Special Topics, vol. 224, no. 9, pp. 1985-1994, 2015.

[3] H. Qiu, L. W. Tian, V. C. Pun, K.-f. Ho, T. W. Wong, and I. T. S. Yu, "Coarse particulate matter associated with increased risk of emergency hospital admissions for pneumonia in Hong Kong," Thorax, vol. 69, no. 11, pp. 1027-1033, 2014.

[4] J. Lasek, Y.-H. Yu, and J. C. S. Wu, "Removal of NOx by photocatalytic processes," Journal of Photochemistry and Photobiology C: Photochemistry Reviews, vol. 14, pp. 29-52, 2013.
[5] J. Huang, C. Zhou, X. Lee et al., "The effects of rapid urbanization on the levels in tropospheric nitrogen dioxide and ozone over East China," Atmospheric Environment, vol. 77, pp. 558-567, 2013.

[6] A. Folli, C. Pade, T. B. Hansen, T. De Marco, and D. E. Macphee, "TiO2 photocatalysis in cementitious systems: insights into self-cleaning and depollution chemistry," $\mathrm{Ce}$ ment and Concrete Research, vol. 42, no. 3, pp. 539-548, 2012.

[7] C. Ren, R. Yang, C. Cheng et al., "Creating breathing cities by adopting urban ventilation assessment and wind corridor plan -the implementation in Chinese cities," Journal of Wind Engineering and Industrial Aerodynamics, vol. 182, pp. 170188,2018

[8] G. L. Guerrini, "Photocatalytic performances in a city tunnel in Rome: NOx monitoring results," Construction and Building Materials, vol. 27, no. 1, pp. 165-175, 2012.

[9] E. Boonen and A. Beeldens, "Photocatalytic roads: from lab tests to real scale applications," European Transport Research Review, vol. 5, no. 2, pp. 79-89, 2013.

[10] M. M. Ballari, Q. L. Yu, and H. J. H. Brouwers, “Experimental study of the NO and NO2 degradation by photocatalytically active concrete," Catalysis Today, vol. 161, no. 1, pp. 175-180, 2011.

[11] G.-J. Park, J.-J. Park, J.-W. Kwak, and S.-W. Kim, "Research on the efficient manufacturing method of photocatalyst concrete according to the type and mixing ratio of photocaralyst," Journal of the korea institute for structural maintenance and inspection, vol. 23, no. 4, pp. 69-77, 2019.

[12] D. Seo and T. S. Yun, "NOx removal rate of photocatalytic cementitious materials with $\mathrm{TiO} 2$ in wet condition," Building and Environment, vol. 112, pp. 233-240, 2017.

[13] E. K. K. Nambiar and K. Ramamurthy, "Air-void characterisation of foam concrete," Cement and Concrete Research, vol. 37, no. 2, pp. 221-230, 2007.

[14] ISO, "Fine ceramics (advanced ceramics, advanced technical ceramics)-Test method for air-purification performance of semiconducting photocatalytic materials-Part 1: Removal of nitric oxide," ISO, vol. 2016, pp. 22197-22201, 2016.

[15] S. Lim, T. D. Nguyen-Phan, and E. W. Shin, "Effect of heat treatment temperatures on photocatalytic degradation of methylene blue by mesoporous titania," Apple. Chem. Eng, vol. 22, no. 1, pp. 61-66, 2011.

[16] G. L. Guerrini and E. Peccati, "Photocatalytic cementitious roads for depollution," in Proceedings of the International RILEM Symposium on Photocatalysis, Environment and Construction Materials, vol. 1, pp. 179-186, Florence, Italy, October 2007. 